\title{
Kinetics and Thermodynamics of Oxidation of Benzhydrol by Tetrabutyl Ammonium Bromochromate in the Presence of Oxalic Acid
}

\author{
S. HEMALATHA ${ }^{1}$, BASIM H. ASGHAR ${ }^{2}$ and S. SHEIK MANSOOR ${ }^{3 *}$ \\ ${ }^{1}$ Research and Development Centre, Bharathiar University, \\ Coimbatore - 641 046, Tamil Nadu, India. \\ ${ }^{2}$ Department of Chemistry, Faculty of Applied Sciences, \\ Umm Al-Qura University, P.O. Box: 9569, Makkah, Saudi Arabia. \\ ${ }^{3}$ Department of Chemistry, C. Abdul Hakeem College (Autonomous), \\ Melvisharam - 632 509, Tamil Nadu, India. \\ ${ }^{*}$ Corresponding author E-mail: smansoors2000@yahoo.co.in
}

http://dx.doi.org/10.13005/ojc/320633

(Received: October 05, 2016; Accepted: November 30, 2016)

\begin{abstract}
The kinetics of oxidation of benzhydrol $(\mathrm{BH})$ by tetrabutylammonium bromochromate (TBABC) was described. Product analysis confirmed the formation of benzophenone. The reaction has been studied in the presence of oxalic acid (OA). The reaction was run under pseudo-first-order conditions. The rate of reaction is first order with respect to TBABC, BH and $\left[\mathrm{H}^{+}\right]$in the presence of oxalic acid (OA). Rates of oxidation of $\mathrm{BH}$ were determined at different temperatures between 298 and $313 \mathrm{~K}$ and the activation parameters were calculated. Further, a suitable mechanism has been proposed based upon the experimental results.
\end{abstract}

Keywords: Tetrabutylammonium bromochromate; Benzhydrol; Oxalic acid; Thermodynamic parameters; kinetics.

\section{INTRODUCTION}

Oxidation is a key reaction for different organic synthesis. Chromium(VI) compounds have proved to be versatile reagents capable of oxidizing almost every oxidiasable functional group. A number of new chromium(VI) containing compounds, with heterocyclic bases, like isoquinolinium bromochromate ${ }^{1}$, triphenylmethylposphonium chlorochromate ${ }^{2}$, prolinium chlorochromate ${ }^{3}$, tripropylammonium fluorochromate ${ }^{4}$, benzimidazolium fluorochromate ${ }^{5}$, quinolinium 
chlorochromate ${ }^{6}$, tetrahexylammonium bromochromate $^{7}$, 4-benzylpyridinium fluorochromate ${ }^{8}$, tetraethyl ammonium bromochromate ${ }^{9}$ and tetrabutylammonium bromochromate ${ }^{10}$ have been developed in recent years to improve the selectivity of oxidation of organic compounds.

The kinetics of oxidation of benzhydrols has been studied by many reagents such as 2,2'-bipyridyl$\mathrm{Cu}(\mathrm{II})$ permanganate ${ }^{11}$, pyridinium chlorochromate ${ }^{12}$, chloramine- $T^{13}, N$-bromo succinimide ${ }^{14,15}, \mathrm{TI}(\mathrm{III})^{16}$ and $\mathrm{N}$-bromopthalimide ${ }^{17}$. However, the kinetics of oxidation of benzhydrol by TBABC, a $\mathrm{Cr}(\mathrm{VI})$ reagent has not yet been studied. In continuation of our study for the oxidation of benzhydrol ${ }^{18,19}$, we studied the kinetics of oxidation of benzhydrol by TBABC in the presence of oxalic acid (OA). A probable mechanism for the oxidation is also studied.

\section{EXPERIMENTAL}

\section{Materials}

Tetrabutylammonium bromide and chromium trioxide were obtained from Fluka (Buchs, Switzerland). Benzhydrol (SRL, AR) and oxalic acid (Aldrich) were used after repeated crystallization from methanol. Acetic acid was purified by standard method and the fraction distilling at $118^{\circ} \mathrm{C}$ was collected.

\section{Preparation of tetrabutylammonium bromochromate, $\left[\mathrm{N}\left(\mathrm{C}_{4} \mathrm{H}_{9}\right)_{4}\right] \mathrm{CrO}_{3} \mathrm{Br}$}

Tetrabutylammonium bromochromate ( $\mathrm{VI})$, $\left[\mathrm{N}\left(\mathrm{C}_{4} \mathrm{H}_{9}\right)_{4}\right] \mathrm{CrO}_{3} \mathrm{Br}$ was easily prepared ${ }^{10}$ as follows: Chromium (VI) oxide $(1 \mathrm{~g}, 10 \mathrm{mmol}$ ) was dissolved in $\mathrm{MeCN}$ and this solution was added to a solution of tetrabutylammonium bromide $(3.22 \mathrm{~g}, 10 \mathrm{mmol})$ in $\mathrm{MeCN}$ under stirring at room temperature until an orange precipitate was formed. After $2 \mathrm{~h}$ stirring, the mixture was filtered. The solvent was evaporated at reduced pressure and the remaining solid was separated.

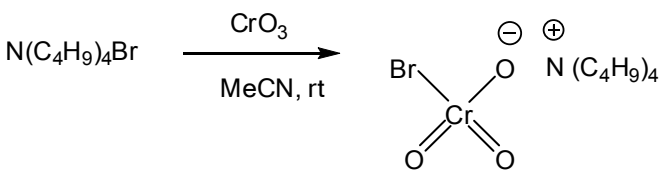

Tetrabutyl ammonium bromide

Tetrabutyl ammonium bromochromate

\section{Kinetic procedure}

Reactions were carried out under pseudo first-order conditions with a known excess of [benzhydrol]o over [TBABC] o at constant temperature using $50 \%$ acetic acid $-50 \%$ water $(v / v)$. A decrease in [TBABC] has been followed by spectrophotometric method using UV-Vis spectrophotometer, Shimadzu UV-1800 model.

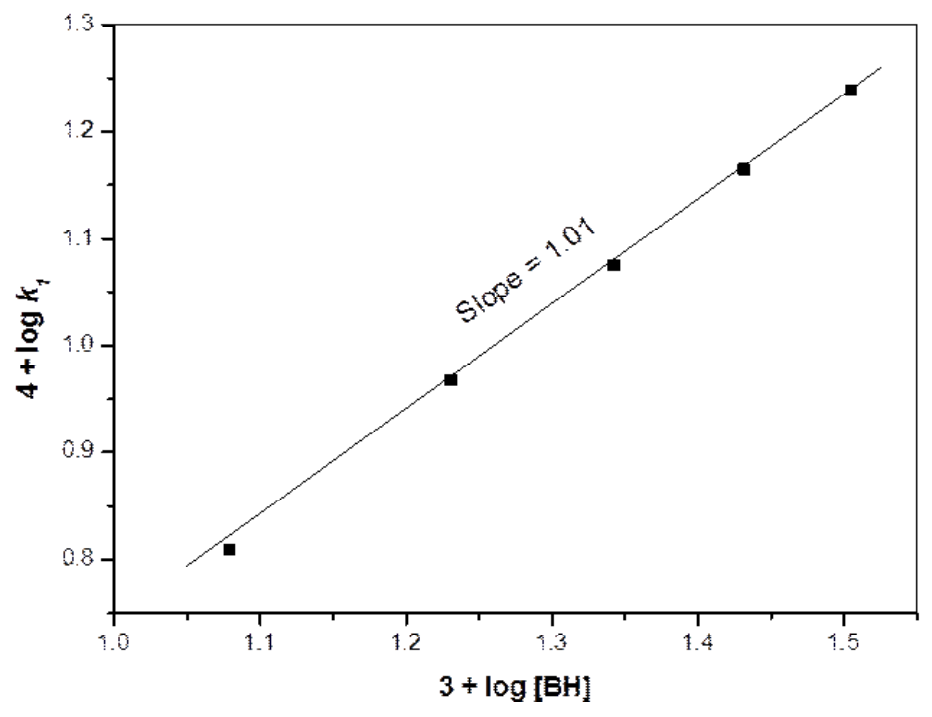

Fig. 1: Showing order plot of benzhydrol for the oxidation of benzhydrol by TBABC in the presence of oxalic acid 


\section{Product analysis}

Product analysis was carried under kinetic conditions. In a typical experiment, benzyhrol $(1.8 \mathrm{~g}$, $0.01 \mathrm{~mol})$ and TBABC $(8.4 \mathrm{~g}, 0.02 \mathrm{~mol})$ were made up to $100 \mathrm{ml}$ of the solvent ( $50 \%$ acetic acid -50 $\%$ water) and kept in the dark for $24 \mathrm{~h}$ to ensure completion of the reaction. The solution was then treated with an excess $\left(200 \mathrm{~cm}^{3}\right)$ of a saturated solution of 2, 4- dinitro phenyl hydrazine in $2 \mathrm{~mol}$ $\mathrm{dm}^{-3} \mathrm{HCl}$ and kept overnight in a refrigerator. The solvent was removed and the precipitated 2, 4 - dinitro phenyl hydrazone (DNP) was filtered and recrystallised from ethanol. The identity of product was established by comparing the m.p. of the DNP derivative with the literature value. The m.pt of DNP was $235-236^{\circ} \mathrm{C}$. This value is very close to $\mathrm{m}$.pt of DNP of benzophenone (lit $237^{\circ} \mathrm{C}$ ).

\section{Stoichiometric studies}

The stoichiomety of the reaction was determined by carrying out several sets of experiments with varying amounts of TBABC largely in excess

Table 1: Rate constants for the oxidation of benzhydrol in the presence of oxalic acid by TBABC in aqueous acetic acid medium at $303 \mathrm{~K}^{\mathrm{a}}$

\begin{tabular}{|c|c|c|c|c|}
\hline $\begin{array}{l}10^{3}[\mathrm{TBABC}] \\
\left(\mathrm{mol} \mathrm{dm}^{-3}\right)\end{array}$ & $\begin{array}{c}10^{2}[\mathrm{BH}] \\
\left(\mathrm{mol} \mathrm{dm}^{-3}\right)\end{array}$ & $\begin{array}{c}{\left[\mathrm{H}^{+}\right]} \\
\left(\mathrm{mol} \mathrm{dm}^{-3}\right)\end{array}$ & $\begin{array}{c}10^{3}[\mathrm{OA}] \\
\left.(\mathrm{mol} \mathrm{dm})^{-3}\right)\end{array}$ & $\begin{array}{c}10^{4} k_{1}^{b} \\
\left(s^{-1}\right)\end{array}$ \\
\hline 1.0 & 2.2 & 0.28 & 0.0 & 8.40 \\
\hline 1.0 & 2.2 & 0.28 & 2.0 & 9.80 \\
\hline 1.0 & 2.2 & 0.28 & 4.0 & 10.86 \\
\hline 1.0 & 2.2 & 0.28 & 6.0 & 11.88 \\
\hline 1.0 & 2.2 & 0.28 & 8.0 & 13.12 \\
\hline 1.0 & 2.2 & 0.28 & 10.0 & 14.40 \\
\hline 0.5 & 2.2 & 0.28 & 6.0 & 11.80 \\
\hline 1.5 & 2.2 & 0.28 & 6.0 & 11.89 \\
\hline 2.0 & 2.2 & 0.28 & 6.0 & 11.84 \\
\hline 2.5 & 2.2 & 0.28 & 6.0 & 11.82 \\
\hline 1.0 & 1.2 & 0.28 & 6.0 & 6.44 \\
\hline 1.0 & 1.7 & 0.28 & 6.0 & 9.28 \\
\hline 1.0 & 2.7 & 0.28 & 6.0 & 14.60 \\
\hline 1.0 & 3.2 & 0.28 & 6.0 & 17.34 \\
\hline 1.0 & 2.2 & 0.12 & 6.0 & 4.92 \\
\hline 1.0 & 2.2 & 0.20 & 6.0 & 8.42 \\
\hline 1.0 & 2.2 & 0.36 & 6.0 & 15.20 \\
\hline 1.0 & 2.2 & 0.44 & 6.0 & 18.50 \\
\hline 1.0 & 2.2 & 0.28 & 6.0 & $11.80^{\circ}$ \\
\hline 1.0 & 2.2 & 0.28 & 6.0 & $8.76^{d}$ \\
\hline
\end{tabular}

${ }^{a}$ As determined by a spectrophotometric technique following the disappearance of oxidant

$10^{2}[\mathrm{BH}]=2.2 \mathrm{~mol} \mathrm{dm}^{-3} ; \quad 10^{3}[\mathrm{TBABC}]=1.0 \mathrm{~mol} \mathrm{dm}^{-3} ;\left[\mathrm{H}^{+}\right]=0.28 \mathrm{~mol} \mathrm{dm}^{-3}$

Solvent composition: $50 \%$ Acetic acid $-50 \%$ Water $(\mathrm{v} / \mathrm{v})$

${ }^{\mathrm{b}}$ Estimated from pseudo-first order plots over $80 \%$ reaction

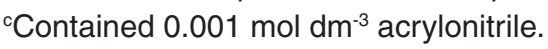

dIn the presence of $0.003 \mathrm{~mol} \mathrm{dm}^{-3} \mathrm{Mn}(\mathrm{II})$. 
over benzhydrol. The estimation of unreacted TBABC showed that the following reaction

$$
\begin{aligned}
& 3\left(\mathrm{C}_{6} \mathrm{H}_{5}\right)_{2} \mathrm{CHOH}+2 \mathrm{Cr}(\mathrm{VI}) \rightarrow 3\left(\mathrm{C}_{6} \mathrm{H}_{5}\right)_{2} \mathrm{CO}+6 \mathrm{H}^{+}+ \\
& 2 \mathrm{Cr}(\mathrm{III})
\end{aligned}
$$

\section{RESULTS AND DISCUSSION}

The oxidation of benzhydrol by TBABC has been conducted in 50\% acetic acid and 50\% water medium at $303 \mathrm{~K}$, under pseudo first order conditions and the result obtained were discussed in the following paragraphs.

\section{Effect of varying OA concentration}

The concentration of oxalic acid is varied in the range of $0.0 \times 10^{-3}$ to $10.0 \times 10^{-3} \mathrm{~mol} \mathrm{dm}^{-1}$ at constant [TBABC], $[\mathrm{BH}]$ and $\left[\mathrm{H}^{+}\right]$at $303 \mathrm{~K}$ and the rates were measured (Table -1$)$. When increasing the concentration of oxalic acid, the rate linearly increases.

Effect of varying TBABC concentration in the presence of OA

The values of $k_{1}$ were calculated in the presence of $6.0 \times 10^{-3} \mathrm{~mol} \mathrm{dm}^{-3}$ of oxalic acid. The concentration of TBABC was varied in the range of $0.5 \times 10^{-3}$ to $2.5 \times 10^{-3} \mathrm{~mol} \mathrm{dm}^{-1}$ at constant $[\mathrm{BH}]$, $\left[\mathrm{H}^{+}\right],[\mathrm{OA}]$ at $303 \mathrm{~K}$ and the rates were measured (Table - 1). At various concentrations of TBABC, the $k_{1}$ values remains constant. This confirms the first order dependence on TBABC.

Table 2: Pseudo-first order rate constants for the oxidation of benzhydrol by TBABC at various percentage of acetic acid-water medium in the presence of Oxalic acid at various temperatures

\begin{tabular}{lccccc}
\hline $\begin{array}{l}\% A c O H \\
\mathbf{H}_{2} \mathbf{O} \\
(\mathbf{v} / \mathbf{v})\end{array}$ & $\begin{array}{l}\text { Dielectric } \\
\text { constant }\end{array}$ & $\mathbf{2 9 8} \mathbf{K}$ & $\mathbf{3 0 3} \mathbf{K}$ & $\mathbf{3 0 8} \mathbf{K}$ & $\mathbf{3 1 3} \mathbf{~ K}$ \\
\hline $30-70$ & 72.0 & 7.08 & 9.42 & 12.52 & 16.66 \\
$40-60$ & 63.3 & 8.22 & 10.76 & 14.40 & 19.26 \\
$50-50$ & 56.0 & 8.90 & 11.88 & 15.80 & 21.08 \\
$60-40$ & 45.5 & 11.18 & 14.76 & 19.50 & 25.72 \\
$70-30$ & 38.5 & 13.60 & 18.14 & 24.12 & 32.08 \\
\hline
\end{tabular}

$10^{2}[\mathrm{BH}]=2.2 \mathrm{~mol} \mathrm{dm}^{-} ; 10^{3}[\mathrm{TBABC}]=1.2 \mathrm{~mol} \mathrm{dm}^{-3} ; 10^{3}[\mathrm{OA}]=6.0$ $\mathrm{mol} \mathrm{dm} \mathrm{m}^{-3} ; 10\left[\mathrm{H}^{+}\right]=2.8 \mathrm{~mol} \mathrm{dm}^{-3}$

Table 3: Second order rate constants and activation parameters for the oxidation of benzhydrol by

\begin{tabular}{|c|c|c|c|c|c|c|c|c|}
\hline $\begin{array}{l}\% \mathrm{AcOH} \\
\mathrm{H}_{2} \mathrm{O} \\
(\mathrm{v} / \mathrm{v})\end{array}$ & $298 \mathrm{~K}$ & $\left(\mathrm{dm}^{3} \mathrm{mc}\right.$ & $308 \mathrm{~K}$ & $313 \mathrm{~K}$ & $\begin{array}{c}\mathrm{E}_{a} \\
\left(\mathrm{kJmol}^{-1}\right)\end{array}$ & $\begin{array}{c}-\Delta \mathbf{S}^{\#} \\
\left(\mathrm{JK}^{-1} \mathrm{~mol}^{-1}\right)\end{array}$ & $\begin{array}{c}\Delta \mathbf{H}^{\#} \\
\left(\mathrm{kJmol}^{-1}\right)\end{array}$ & $\begin{array}{c}\Delta \mathbf{G}^{\#} \\
\left(\mathrm{kJmol}^{-1}\right) \\
(\text { at } 303 \mathrm{~K})\end{array}$ \\
\hline $30-70$ & 3.22 & 4.28 & 5.69 & 7.57 & 44.42 & $133.43 \pm 1.2$ & $41.74 \pm 0.4$ & $82.16 \pm 0.8$ \\
\hline $40-60$ & 3.77 & 4.89 & 6.55 & 8.75 & 43.84 & $134.00 \pm 1.8$ & $41.16 \pm 0.6$ & $81.76 \pm 1.2$ \\
\hline $50-50$ & 4.05 & 5.40 & 7.18 & 9.58 & 44.61 & $130.56 \pm 0.9$ & $41.93 \pm 0.3$ & $81.48 \pm 0.6$ \\
\hline $60-40$ & 5.08 & 6.71 & 8.86 & 11.69 & 43.08 & $132.48 \pm 1.5$ & $40.78 \pm 0.5$ & $80.92 \pm 1.0$ \\
\hline 70-30 & 6.18 & 8.25 & 10.96 & 14.58 & 44.96 & $126.54 \pm 2.4$ & $42.31 \pm 0.8$ & $80.65 \pm 1.6$ \\
\hline
\end{tabular}
TBABC at various percentage of acetic acid-water medium in the presence of Oxalic acid

$10^{2}[\mathrm{BH}]=2.2 \mathrm{~mol} \mathrm{dm}^{-3} ; 10^{3}[\mathrm{TBABC}]=1.2 \mathrm{~mol} \mathrm{dm}^{-3} ; 10^{3}[\mathrm{OA}]=6.0 \mathrm{~mol} \mathrm{dm}^{-3} ; 10\left[\mathrm{H}^{+}\right]=2.8 \mathrm{~mol} \mathrm{dm}^{-3}$ 
Effect of varying benzhydrol concentration in the presence of OA

The concentration of $\mathrm{BH}$ is varied in the range of $1.2 \times 10^{-2}$ to $3.2 \times 10^{-2} \mathrm{~mol} \mathrm{dm}^{-1}$ at $303 \mathrm{~K}$ and keeping all other reactant concentrations as constant and the rates were measured (Table - 1). The $k_{1}$ value linearly increases on increasing the concentration of benzhydrol. The plot of log $k_{1}$ versus log $[\mathrm{BH}]$ gave unit slope for $\mathrm{BH}$ (Fig. 1). Under pseudo-first-order conditions, the plot of $k_{1}$ versus $[\mathrm{BH}]$ is linear passing through origin. These results confirm the first-order nature of the reaction with respect to $[\mathrm{BH}]$ in the presence of OA.

\section{Effect of varying perchloric acid concentration in the presence of OA}

Perchloric acid has been used as a source of hydrogen ion in reaction medium. The concentration of $\mathrm{H}^{+}$was varied in the range 0.12 to $0.44 \mathrm{~mol} \mathrm{dm}^{-1}$ keeping all other reactant concentration as constant at $303 \mathrm{~K}$ and the rates were measured (Table - 1 ). The $k_{1}$ value linearly

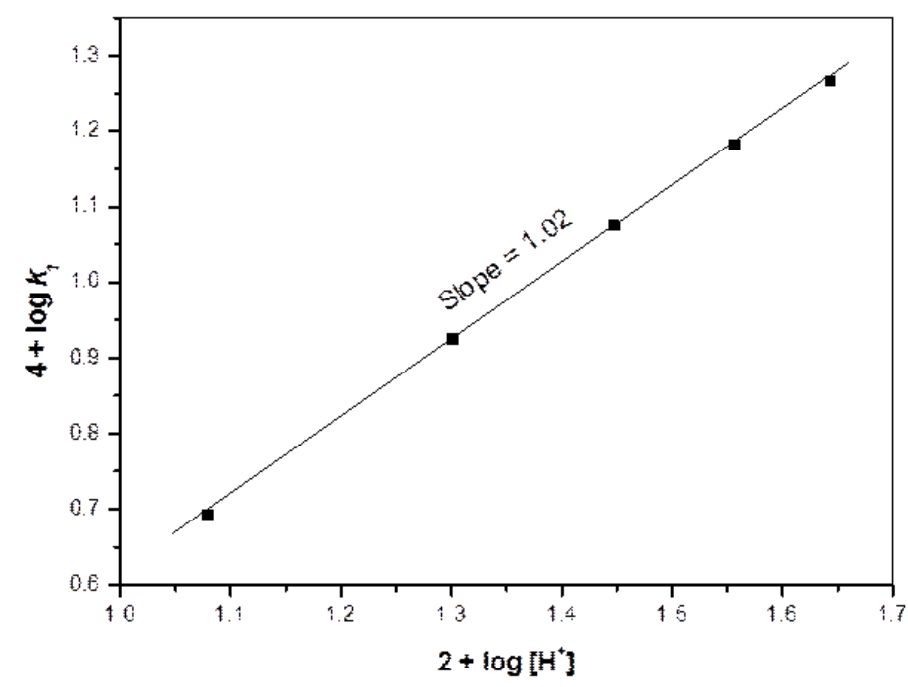

Fig. 2: Showing order plot of perchloric acid for the oxidation of benzhydrol by TBABC in the presence of oxalic acid

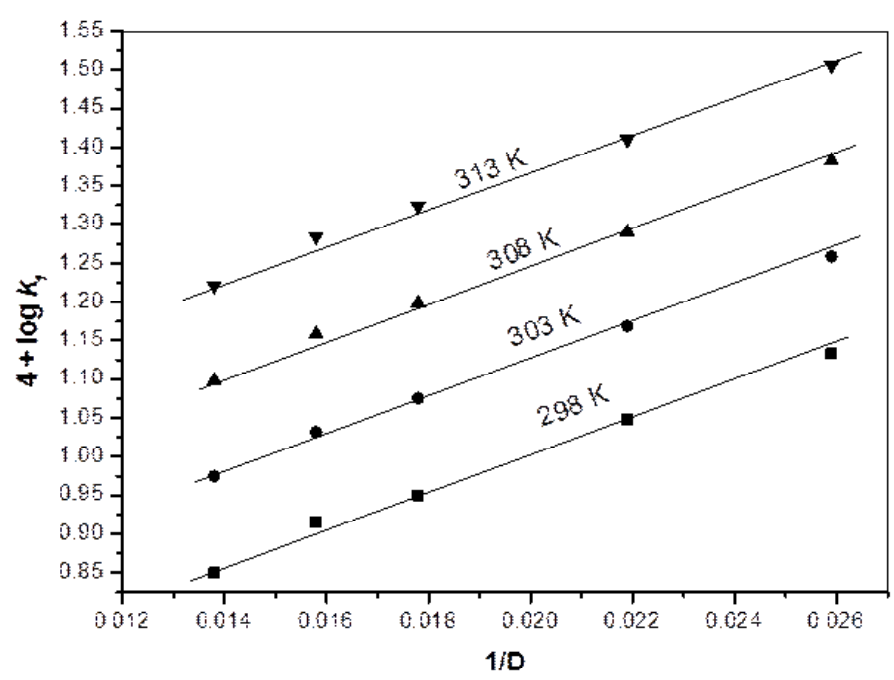

Fig. 3: Plot of 1/D against log $k 1$ showing effect of solvent polarity at various temperatures in the presence of oxalic acid 
increases on increasing the concentration of $\mathrm{H}^{+}$. The plot of $\log k_{1}$ versus $\log \left[\mathrm{H}^{+}\right]$is a straight line with unit slope (Fig. 2). Therefore, order with respect to $\mathrm{H}^{+}$ is one for $\mathrm{BH}$ in the presence of OA. TBABC may become protonated in the presence of acid and the protonated TBABC may function as an effective oxidant.

\section{Effect of acrylonitrile and $\mathrm{MnSO}_{4}$}

Oxidation of benzhydrol, under nitrogen atmosphere, failed to induce polymerization of acrylonitrile. Further, addition of acrylonitrile had no effect on the rate (Table -1$)$. However, the addition of $\mathrm{Mn}$ (II) $\left(0.003 \mathrm{~mol} \mathrm{dm}^{-3}\right)$, in the form of $\mathrm{MnSO}_{4}$ retards the rate of oxidation. Hence, the presence of $\mathrm{Cr}(\mathrm{IV})$ intermediate in the oxidation of benzhydrol by $\mathrm{Cr}(\mathrm{VI})$ is confirmed ${ }^{20}$.

\section{Effect of Acidity}

The reaction is catalyzed by hydrogen ions (Table 1). The acid-catalysis may well be attributed to a protonation of TBABC to give a stronger oxidant and electrophile.

$$
\mathrm{O}_{2} \mathrm{CrBrO}^{-} \mathrm{N}^{+}\left(\mathrm{C}_{4} \mathrm{H}_{9}\right)_{4}+\mathrm{H}^{+}
$$

$(\mathrm{OH}) \mathrm{CrBrO}^{-} \mathrm{N}^{+}\left(\mathrm{C}_{4} \mathrm{H}_{9}\right)_{4}$

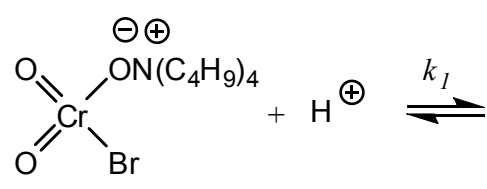<smiles></smiles>

TBABC<smiles>O=C(O)C(=O)O</smiles>

Oxalic acid<smiles></smiles><smiles>[Y]C=C</smiles><smiles>C1CCCCC1</smiles><smiles>O=C1OC(=O)C(=O)O1</smiles><smiles>O=C1OC(=O)C(=O)O1</smiles>

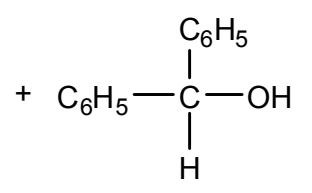<smiles>C=C=[As]</smiles>

$\left(\mathrm{C}_{1}\right)$

Benzhydrol<smiles>O=C1OC(=O)[Ge](O)(OC(c2ccccc2)c2ccccc2)O1</smiles><smiles></smiles><smiles>O=C(CCCC=[O+])c1ccccc1</smiles><smiles>O=C1OC(=O)C(=O)O1</smiles>

Scheme 1: Mechanism of oxidation of benzhydrol by TBABC in the presence of oxalic acid 
The formation of a protonated $\mathrm{Cr}(\mathrm{VI})$ species has earlier been postulated in the reactions of structurally similar $\mathrm{PCC}^{21}$ and $\mathrm{PFC}^{22}$.

\section{Effect of solvent polarity on reaction rate in the presence of OA}

The oxidation of $\mathrm{BH}$ has been studied in the binary mixture of acetic acid and water as the solvent medium in the presence of $\mathrm{OA}$. The concentration of acetic acid was varied from $30 \%$ to $70 \%$ and the rate were measured. The reaction rate increased remarkably with the increase in the proportion of acetic acid in the solvent medium (Table - 2). Positive slope of $\log k_{1}$ versus $1 / \mathrm{D}$ plot indicates that the reaction involves a cation-dipole type of interaction in the rate determining $\operatorname{step}^{23}$ (Fig. 3).

\section{Determination of activation parameters in the presence of OA}

Rates of oxidation of benzhydrol were determined at different temperatures between 298 and $313 \mathrm{~K}$ at various percentage of acetic acid-water medium in the presence of oxalic acid. Various activation parameters were calculated and the values were presented in Table -3. The entropy of activation is negative for benzhydrol in the presence of oxalic acid.
Mechanism of oxidation in the presence of OA

The findings with oxalic acid can be explained by considering the reaction mechanism outlined in Scheme - 1. Oxalic acid readily form complexes $\left(\mathrm{C}_{1}\right)$ with $\mathrm{Cr}(\mathrm{VI})$ which are active oxidants ${ }^{24}$. The $\left(C_{1}\right)$ complex then reacts with benzhydrol to form $\left(\mathrm{C}_{2}\right)$. The complex $\left(\mathrm{C}_{2}\right)$ is ternary complex and it undergoes redox decomposition by two electron transfer. The rate determining step involves a cyclic transition state. In the rate determining step there is a simultaneous rupture of $\mathrm{C}-\mathrm{C}$ and $\mathrm{C}-\mathrm{H}$ bonds to give a benzophenone and the $\mathrm{Cr}(\mathrm{IV})-\mathrm{OA}$ complex.

\section{CONCLUSIONS}

The kinetics of oxidation of benzhydrol has been investigated in the presence of oxalic acid by spectrophotometric method. The values of $k_{1}$ were calculated in the presence of $6.0 \times 10^{-3} \mathrm{~mol} \mathrm{dm}^{-3}$ of oxalic acid. The oxidation of benzhydrol by TBABC is first order each with respect to the benzhydrol, TBABC and hydrogen ion. The lowering of dielectric constant of reaction medium increases the reaction rate significantly. The reaction does not show the polymerization, which indicates the absence of free radical intermediate in the oxidation.

\section{REFERENCES}

1. Vibhute, A.Y.; Patwari, S. B.; Khansole, S. V.; Vibhute, Y. B. Chin. Chem. Lett. 2009, 20, $256-260$

2. Hajipour, A. R.; Khazdooz, L.; Ruoho, A. E. J. Iranian Chem. Soc. 2005, 2, 315-318

3. Mamaghani, M.; Shirini, F.; Parsa, F. Russ. J. Org. Chem. 2002, 38, 1113-1115

4. Yogananth, A.; Mansoor, S.S. Oriental J. Chem. 2015, 31, 17-23

5. Malik, V. S.; Vannamuthu, I.; Shafi, S. S.; Mansoor, S. S. Oriental J. Chem. 2015, 31, 77-83

6. Elango, K. P.; Jayanthi, G.; Vijayakumar, G. J. Serb. Chem. Soc. 2002, 67, 803 -808

7. Mansoor, S.S.; Asghar, B.H. J. Indian. Chem. Soc. 2013, 90, 1395 - 1401

8. Ozgün, B.; Yaylaoglu, A.; Sendil, K. Monatsh. Chem. 2007, 138, 161 - 163

9. Mansoor, S.S.; Shafi, S.S. Z. Phys. Chem.,
2011, 225, 249 - 265

10. Ghammamy, G.; Mehrani K.; Afrand, H.; Hajighahramani, M. Afr. J. Pure Appl. Chem. 2007, 1, 8-10

11. Grover, A.; Varshney, S.; Banerji, K.K. Indian J. Chem. 1996, 35B, $171-178$

12. Venkataraman, K. S.; Sundaram, S.; Venkatasubramanian, N. Indian J. Chem. 1978, 16B, $84-88$

13. Rangappa, K.S.; Ramachandran, H.; Mahadevappa, D.S. J. Phys. Org. Chem. 1997, 10, 159 - 166

14. Venkatasubramanian, N.; Thiagarajan, V. Can. J. Chem. 1969, 47, $694-697$

15. Hiran, B.L.; Malkani, R. K.; Rathore, N. Kinet. Catal. 2005, 46, $360-365$

16. Hiran, B. L.; Malkani, R. K.; Nalwaya, N.; Chand, K.; Rathore, N. Oxid. Commun. 2004, 27, $98-102$ 
17. Jagdeesh, B.; Archana, C.; Balaji, M.; Fulchand, C.; Mazahar, F.; Milind, U. J. Indian Chem. Soc. 2009, 86, $481-484$

18. Mansoor, S. S.; Shafi, S. S.; Ahmed, S.Z. Arab. J. Chem. 2013, http://dx.doi.org/10.1016/j. arabjc.2013.02.005

19 Mansoor, S. S.; Shafi, S. S. Reac. Kinet. Mech. Cat. 2010, 100, $21-31$

20. Karunakaran, C.; Suresh, S. J. Phys. Org.
Chem. 2004, 17, 88-93

21. Sharma, V.; Sharma, P. K.; Banerji, K. K. J. Indian Chem. Soc. 1997, 74, 607 - 611

22. Sharma, V.; Sharma, P.K.; Banerji, K. K. J. Chem. Research (S). 1996, 290 - 291

23. Amis, E. S. Solvent Effects on Reaction Rates and Mechanisms. Academic Press, New York, 1967, 42

24. Vanangamudi, G.; Srinivasan, S. E - J. Chem., 2009, 6(3), 920 - 927 